\title{
Mother tongue education in primary teacher education in Kenya: a language management critique of the quota system
}

\author{
Munene Mwaniki
}

Correspondence: mwanikimm@ufs.ac.za

University of the Free State, Bloemfontein, South Africa

\begin{abstract}
Mother tongue education (MTE) has been a subject of rigorous debate for more than half a century, in both industrialised and developing societies. Despite disparate views on MTE, there is an uneasy consensus on its importance in educational systems, especially in the foundational years. Using the Language Management Framework, the article provides a critical appraisal of MTE discourses in relation to primary teacher education and the quota system of student teacher selection and teacher deployment in Kenya. The article argues that from a language management perspective, these two mechanisms are critical in sustaining and promoting MTE in Kenya, and possibly elsewhere.
\end{abstract}

\section{Introduction}

Despite many studies that show that it makes good sense to begin a child's education in his or her own language, the age-old tradition of teaching a child in a language other than the first language or teaching in a child's first language only in the lower classes of primary school still persists in many African countries. This practice has led to poor scholastic attainment, often manifested in high repeat or failure rate, poor performance in examinations, and maladjustment to the world of work. Marginalisation of African languages is an inevitable outcome since they are not used for meaningful education. A look at other parts of the world shows that what goes on in Africa in terms of language of education is an aberration. Even small countries in Europe use their languages as languages of instruction, even if the children have to learn another language such as English or French. This is not just a matter of national pride; it is a sound educational principle to proceed from the familiar to the new. This is precisely what linguists and educationists have been advocating for Africa. The fears of a multiplicity of languages and the uneconomic cost of teaching in several languages, which are often invoked to counter the feasibility of education in indigenous languages, have been shown to be pseudo problems, as strategies can be, and have been, devised for selection and development of languages as well as for production of teaching materials at relatively reasonable cost (Bamgbose 2009, p. 13).

The above quotation easily sums up Mother Tongue Education (hereafter, MTE) quandary in many an African state. The article interrogates this quandary in Kenya 
from a language management perspective. From this perspective, primary teacher education and the quota system are identified as approaches and/or frameworks that can be harnessed to address the MTE quandary in Kenya, and possibly elsewhere.

The discussion is presented in five parts. The first part presents the theory and practice of language management and an overview of the debates and controversies attendant to quotas in education in Africa. The second part presents a general overview of the discourse on MTE and culminates in a synopsis of MTE in Kenya. The third part discusses primary teacher education in Kenya as well as the quota system in Kenya's education. Part four interrogates the positive role that is played by primary teacher education and the quota system in MTE in Kenya. The final part highlights policy and pragmatic lessons that can be drawn from the positive role of quality primary teacher education and the quota system in MTE in Kenya.

\section{Language management: exploratory discussion of theory and practice}

Language management theory and practice have long been developing. A key figure in the epistemology of language management theory and practice is J. V. Neustupny, who has written extensively on the subjects since the 1960s (cf. Neustupny 1968; 1978; 1983; 1984; 1985; 1989a; 1989b; 1993; 1995; 1999). Other contributions to this theory and practice include Mwaniki (2004) and Spolsky (2009).

According to Neustupny and Nekvapil (2003), language management theory originates in the "language correction" theory developed in the 1970s and 1980s mainly by Neustupny and Jernudd, and it grew as an extension and adjustment of language planning theory. In this theory, the word management refers to a wide range of acts of attention to "language problems". In the language planning theory of the 1960s, 1970s and 1980s "language problems" were problems of language in the narrow sense of the word. "Current language management theory aims to incorporate not only the whole of language, defined in the traditional narrow sense, but a wide range of additional problems implicating discourse and communication in intercultural contact situations" (Neustupny and Nekvapil 2003, p. 185. Further, Neustupny and Nekvapil (2003) distinguish between simple and organised management of language. Language management theory maintains that, in principle, language problems originate in simple management and from there they are transferred to organised management. Finally, "the results of organised management are again transferred to discourse: without correcting individual discourse, the whole management process would make little sense" (Neustupny and Nekvapil 2003), p. 185.

The second prominent feature of language management theory, according to (Neustupny and Nekvapil 2003), pp. 185 - 186, is its processuality (Neustupny and Nekvapil 2003), p. 185. Both simple and organised management are seen as developing in a number of stages. They commence with the deviation from the norm, with different participants often possessing different norms or 'expectations'. Following the deviation stage, the deviation may be noted: a noted deviation may be evaluated, and subsequently an adjustment plan selected. In the last stage, the plan may be implemented. The third feature of language management theory is the establishment of a hierarchy between language (in the narrow sense), communication and socioeconomic management. "Language management alone makes little sense. A fourth feature is the insistence on the recognition of the multiplicity 
of interests within a community. Language management is not a valueless, objective 'scientific' process" (Neustupny and Nekvapil 2003), p. 186.

Mwaniki (2004) identifies four aspects of such a framework, namely: the theory; the method; the discipline; and the practice. Language management theory is a complex of theoretical precepts deriving from decision-making theory, sociological and linguistic theories, modernisation theory, systems theory, critical theory, management theory, phenomenology and human development theory, all seeking to understand and explain the interactive dynamics of language in society and language and society. Language management theory, especially in multilingual societies, aims at formulating approaches that can be deployed to address language-related challenges.

Language management method is both a complex of methods and a particular way of doing linguistic and social science. As a discipline, language management is an organized body of knowledge that preoccupies itself with questions relating to the theoretical adequacy of language policy and planning theory and method; and how these impact on language policy and planning implementation, especially in multilingual settings. As a practice, language management is a critical and creative deployment of strategies designed to address language-related challenges and harness language resources, especially in multilingual settings. As such, its ultimate goal is the enlargement of people's choices, whether at the macro levels of governance, development and democracy or at the micro levels of individual freedom and advancement, and service access broadly defined.

Another contribution to language management theory and practice is Spolsky (2009). In this contribution that takes a processual approach that conceptualises language management theory and practice as a logical development from language policy and planning theory and practice, Spolsky (2009) submits that language policy is all about choices and the goal of a theory of language policy is to account for the choices made by individual speakers on the basis of rule-governed patterns recognised by the speech community (or communities) of which they are members. "Some of these choices are the result of management, reflecting conscious and explicit efforts by language managers to control the choices" (Spolsky 2009), p. 1. Further, language management requires a detailed understanding of multilingualism and social structure, as well as of multidimensional social and demographic space (Spolsky 2009), p. 260.

Within the context of the current discussion, mother tongue education is understood to encompass the use of mother tongues for the education of children in formal institutions, i.e. schools. This view does not imply that the crucial role of non-formal institutions like the home and neighbourhood in mother tongue education is not acknowledged. Rather, the view is deliberate because of the variables under consideration in this discussion - quality teacher education and the quota system; and how these two variables impact on MTE. Admittedly, quality teacher education and the quota system intersect with MTE within formal institutions, i.e. schools.

\section{Quotas in education in Africa: debates and controversies}

The debate on quotas, defined as differential access policies (Gould 1974), in African education has been alive and well for as long as formal education has been around on the continent. Considering for a fact that in many parts of Africa formal education is, 
in the words of Foster (1980), p. 201 perhaps the most important contemporary mechanism of stratification and redistribution and does not just simply reflect extant patterns of social and economic differentiation, but rather powerful independent forces in the creation of new and emergent groupings based on the variable possession of power, wealth, and prestige; these policies have also been accompanied by a fair share of controversies. As a way of introducing the discussion on quotas later in the article, some of the debates and controversies around quotas in education in Africa as found in the literature are sampled in this section. The discussion ends with a mention of how the quota system works in practice in Kenyan education.

In one of the earliest studies to ever explore the issue of quotas in African education, Clignet (1970), p. 431 - 432 documents that in pre-independence Africa, many territories tried to obtain an ethnically even distribution of school populations by introducing a system of ethnic quotas or by placing new schools in regions predominantly occupied by underprivileged peoples. As such, from the inception of formal education systems in Africa, the debate on quotas and concomitant policies have largely been framed in political terms. With regard to this, and with a specific reference to Eastern Africa, Gould (ibid, p. 374) notes that 'opportunity to attend schools varies considerably from one area of each country to another and from one ethic and social group to another. A central political issue has, therefore, been concerned with promoting geographical and social equality of opportunity by reducing considerable regional and social disparities in access to education which exist where education is not universal'. Immediately after independence, such policies were seen as important in mediating the tensions between different races and ethnic groups. This remains true deep into the second half century of political independence in much of Africa. In other instances, a system of regional quotas is seen as having 'the effect of reducing rural/urban imbalance in admissions and creating greater opportunities for socially disadvantaged students (Gould, ibid, p. 386). However, to critics, quotas have been seen as 'discriminating against merit and substituting institutionalised ethnicity and regionalism' (Gould, ibid, p. 375).

Writing on trends and new priorities in economics of education in developing countries Blaug (1979) identifies geographical and social quotas as a basis for educational selection and ultimately as determinants for access to education. From this perspective, quotas are associated with educational reform that seeks to set new priorities as African countries deal with successive social and economic challenges in a fast evolving global milieu. The classification of quotas into geographical (spatial) and social is also shared by Foster (ibid). However, Foster (ibid, p. 206 - 207) cautions that quotas may not be the panacea of addressing all access complexities in African education by observing that 'research indicates that inequalities in the spatial distribution of education which are, in large measure, a function of variable levels of local demand, do not occur in a random or unpredictable fashion: they are systematically linked to other aspects of change; they are extremely long-lasting, and not easily susceptible to major transformation; and in practice, disparities tend to widen rather than diminish at intermediate levels of development'. As such, 'the use of ethnic and socio-economic quotas is one solution, but often such measures turn out to be just as inequitable as those that they intended to remove' (Foster 1980), p. 236.

Other research such as Dovlo (2004) conceptualise quotas as a coping strategy in educating and training of professionals especially in societies that have a history of 
systemic exclusion of certain sections of society from certain professions such as health care education. In such cases, quotas are used because 'pure academic merit has been faulted for producing elitist professionals because candidates coming from deprived communities with poor educational infrastructures are simply unable to compete with candidates from elite urban schools' (Dovlo 2004), p. 13. Echoing earlier research such as the one already cited, and with specific reference to Nigeria, Ukiwo (2007) argues that quotas in education are a means of ameliorating regional, ethnic and religious inequities which when unattended have a debilitating effect on the national project. From this perspective, quotas are an important mechanism in spreading access to education as well as serving strategic national development aspirations such as national integration and cohesion. However, Ukiwo (2007) is also alive to the controversies attendant to quotas in education in Africa including: engendering disunity and polarisation of the country; the questionable redistributive potential of quotas; and the promotion of mediocrity because oftentimes merit is sacrificed at the altar of political imperatives. These broad contours of the debates and controversies around quotas in education in Africa find further corroboration in Tanye (2008) and Morley et al. (2009).

Within the Kenyan education system quotas have been an enduring policy nexus especially in secondary and post-secondary education levels. At the secondary school level, as Yakaboski and Nolan (2011) correctly document, government schools are divided into three categories arranged in a hierarchy with a quota system in place for admission. At the top are the national schools that consist of a tiny minority of prestigious public funded schools, found mostly in Kenya's larger cities. Then there are provincial schools in the middle, and finally the largest and lowest ranking group are the district schools. Under the national school quota system, there must be equal numbers of students from each district in an attempt to address equal access for regional and tribal admissions. Under the current quota system, which has been in place since the 1980s, the provincial schools must admit 85 percent of their students from their localities. Then, district schools absorb the students who do not perform well to join national and provincial schools. Quoting Siringi (2011), Yakaboski and Nolan (2011), p. 5 document that a consequence of this quota system is that it discourages parents from enrolling their children in private primary schools, which have a higher educational quality, but the top national secondary schools can only admit 25 percent from private schools. The quota system extends to primary teacher training colleges. However, the controversies attendant to quotas in Africa's education are also manifest in debates on quotas in Kenyan education system with Opiyo (2010) cited in Yakaboski and Nolan (2011), p. 5 opining that the system perpetuates tribal and ethnic segregation rather than promoting diversity. These controversies notwithstanding, the current discussion holds the informed view that the quota system, especially as applied in primary teacher education especially with regard to student teacher selection and teacher deployment, is critical in sustaining and promoting MTE in Kenya. The discussion returns to this argument toward the end of the article.

\section{Mother tongue education: an overview of a discourse through time}

The UNESCO meeting of specialists on the use of vernacular languages in education in 1951 (UNESCO 1951), whose report was published in 1953, is easily and understandably 
cited as an incipient point in the discourse on MTE. Since then, a lot of research has been done on MTE and literature on the subject abounds. Reviews of this literature can be found in a sizeable percentage of works that tackle the subject of MTE. It is not the purpose of the current overview to replicate these reviews. Rather, this overview seeks to outline the dominant themes in the discourse on MTE. In doing so, the following discussion attempts to propose a taxonomy that captures the width and breadth of the discourse on MTE as embedded in the literature. The discussion adopts the critical, poststructuralist view of discourse as 'ways of understanding and constructing the social world' (Martin-Jones and De Mejia 2008), p. xiii. For the purposes of this discussion, the dominant discourses in MTE can be identified as the historiographical/comparative discourse; the pedagogics/didactics discourse; the policy discourse; the human rights/social justice discourse; and the development discourse. These discourses are briefly elaborated in the following discussion.

\section{Historiographical/comparative discourse}

One of the dominant discourses in MTE is what can be characterised as the historiographical/comparative discourse. From the perspective of historiographical discourse, MTE carries the burden of history and is cognisant of this. The historiographical discourse seeks to locate MTE within historical space. In doing so, it depicts MTE as always being alive to the historical circumstances in which it has evolved; and as being a contributor to the historical circumstances in different polities. This discourse underlines the linking of MTE with state formation, where the entrenchment of MTE in a country's education system is conceptualised as one of the key mechanisms of consolidating the nation state. This view has been especially dominant in the Western conceptualisation of the inextricable relationships between language and the nation state and the role of education in socialisation, usually within a 'unilingual' state. The emergence of multiculturalism has tended to challenge this perspective, but not to replace it. In the West, multiculturalism is strongly associated with a growing realisation of the unintended social and cultural consequences of large-scale immigration. It is a term associated in principle with the values of equality, tolerance, and inclusiveness toward migrants of ethnically different backgrounds. From this perspective, multiculturalism is a social doctrine that distinguishes itself as a positive alternative for policies of assimilation, connoting recognition of the citizenship rights and cultural identities of ethnic minority groups and, more generally, an affirmation of the value of cultural diversity (Kymlycka 1995). It is noteworthy that multiculturalism is a defining feature in the former colonised world. In this part of the world, multiculturalism is a way of life and not an unintended social and cultural consequence of large-scale immigration. The historiographical discourse on MTE in the former colonised world takes cognisance of the disruptive nature of colonialism and colonial languages to the education systems of former colonial polities - with polities defined as autonomous nation-states with specific and entrenched forms of government. It uses the disruptive logic of colonialism and colonial languages as a basis to argue for the recognition and promotion of indigenous languages in education in these polities. In advancing the case for MTE in these former colonial polities, the historiographical discourse traces the historical circumstances attendant to the creation of different nation states and the impact of these 
historical circumstances on MTE; while acknowledging the pervasive multiculturalism and accompanying multilingualism in these polities and the primacy of diversity in creating viable nation states.

Closely related to the historiographical discourse in MTE is the comparative discourse. This discourse seeks to compare MTE regimes in different polities; and in the process identifies the challenges attendant to actualising MTE as well as identifying success stories. In this comparative endeavour, this discourse is alive to the dialectics of history and MTE in different polities. This discourse is anchored on a need to identify and consolidate an inventory of what works and what does not work in MTE, while remaining cognisant of the peculiar circumstances in different polities. This discourse seeks to use both what works and what does not work for MTE as signposts for the actualisation of MTE across polities.

\section{Pedagogics/didactics discourse}

The pedagogic-didactic discourse underlines much of MTE philosophising. In more general terms, the study of education is called pedagogics. However, specifically, pedagogics entails "a study of the phenomena of pedagogy, where pedagogy means the education of a child by a responsible adult person" (Harmse 1982), p. 13. As a part-discipline of pedagogics, "didactics is scientific reflection centring on educative teaching-learning acts in the school and the related aspects such as didactic principles (teaching principles), teaching and learning materials (knowledge) development and teaching methods" (Duminy and Sohnge 1982), p. 22. Among general didactic principles, which include totality, individualisation, interest and motivation, perception, environmental teaching, and selection, mother-tongue teaching features prominently. For children, language provides the power to start, in a much more efficient and differentiated way, a dialogue with their world, and also with the people in their world. Through mother tongue, a child gains a whole cultural heritage, which will, to a large extent, determine his further thinking, feelings, desires and attitudes.

The pedagogic-didactic discourse argues for the primacy of mother tongue in teaching and learning. However, the link between the role of mother tongue in teaching and learning is not a simple and straightforward one. At the beginning of a school career, a child still has a relatively limited knowledge of mother tongue. A child may know enough of the language for his/her own needs at that stage, but ahead lies a great deal of hard work - not only in his/her mother tongue, but also on his mother tongue as a subject. It is only through purposeful and systematic teaching that the linguistic efficiency and skill brought from home can be heightened and extended. The logic of the primacy of mother tongue in teaching and learning is premised on the understanding that mother tongue is the most effective vehicle or carrier of all other things that the child is expected to learn from school. Further, mother tongue is also the basis upon which all other learning is anchored. As Duminy and Sohnge (1982), p. 57 observe:

When language formation is not up to standard, one cannot expect much from the teaching-learning setting. First, the necessary foundation of language formation must be present, and this foundation can never be better laid than within the sphere of the mother tongue. Training in the mother tongue enables the socio-emotional life of the 
child to unfold smoothly, and at the same time helps the child towards independent and logical thinking.

\section{Policy discourse}

Policy, especially public policy, underlies much of the research and writing around MTE. Public policy is defined as "a long series of more or less related choices, including decisions not to act, made by governmental bodies and officials" (Dunn 1981, p. 46). According to Van Der Waldt (2002), pp. 87 - 88:

Policy is larger than a decision. A policy usually involves a series of more specific decisions, sometimes in a rational sequence. Even when the sequence is more erratic, a policy is typically generated by interactions among many, more or less consciously related, decisions. The study of a policy usually involves tracing multiple interactions among many individuals, many groups, and many institutions. Policy also involves action as well as inaction. In other words, policy makers may fail to act and/or take deliberate decisions not to act. Policy as inaction is, however, more difficult to pin down and analyse than policy as action, since it involves perceived behaviour and intent. Policy can be seen as the overarching concept, whilst legislation or acts, regulations, and instructions can be seen as purpose- and process-specific derivatives of public policy.

Underpinned by policy discourse, much of MTE research and literature has preoccupied itself with the following:

i. A description of policies, often language-in-education policies, which inform MTE in many a polity.

ii. A description of the factors that underlie MTE policies in different polities.

iii. A prescriptive rendition of what should be the best MTE policy for different polities.

iv. A bemoaning of the lack of appropriate MTE policies in different polities.

A singular failure of MTE research and literature which is premised on the policy discourse has been the lack of recognition of the political nature of public policy. In many polities, the political infrastructure is controlled by the elites. Unless it further serves the entrenchment of their power, elites do not implement policies that seek to undercut their power. Inasmuch as the foregoing is the rule of the thump everywhere, it is more apparent in the developing world. In these polities, elites [who are often a creation of an educational, economic and political system premised on Western values] often use mother tongue for political mobilisation, but revert back to other languages, especially Western languages, for the business of governance. In exceptional cases where elites agitate for MTE, as is the case with the Afrikaner elite in South Africa, it is because the educational, political and economic fortunes of these elite are inextricably tied to their mother tongue. Regrettably, to many developing world elite, mother tongue does not feature in the project of modernising their countries. The masses in the developing world also view mother tongue with suspicion - as a way of confining them to the lower echelons of educational, political and economic achievement. This is a sad state of affairs, but it is the case. To reverse this trend in the developing world, there is need 
for MTE research that understands the intricacies of public policy processes that underpin MTE with the view of illustrating that MTE does not necessarily undermine the power of the elites, but rather serves the greater good of preparing the active citizens in a modernising democratic state.

\section{Human rights/social justice discourse}

The idea of human rights is one of the most powerful in contemporary social and political discourse. It seeks to overcome divisiveness and sectarianism and to unite people of different cultural and religious traditions in a single movement asserting human values and the universality of humanity, at a time when such values are seen to be under threat from the forces of economic globalisation and religious fanaticism. The idea of human rights, by its very appeal to universally applicable ideas of the values of humanity, seems to resonate across cultures and traditions and represents an important rallying cry for those seeking to bring about a more just, peaceful and sustainable world (Ife 2001).

An important aspect in classifying any claim as a human right is that anything classified as a human right has priority over other claims of right. To make a claim on the basis of human rights, the following criteria must be met:

i. Realisation of the claimed right is necessary for a person or group to be able to achieve their full humanity, in common with others.

ii. The claimed right is seen either as applying to all of humanity, and is something that the person or group claiming the right wishes to apply to all people anywhere, or as applying to people from specific disadvantaged or marginalised groups for whom realisation of that right is essential to their achieving their full human potential.

iii. There is substantial universal consensus on the legitimacy of the claimed right; it cannot be called a 'human right' unless there is widespread support for it across cultural and other divides.

iv. It is possible for the claimed right to be effectively realised for all legitimate claimants. This excludes rights to things that are in limited supply.

v. The claimed right does not contradict other rights (Ife 2001), pp. $10-11$.

The above criteria have largely framed the human rights discourse in MTE. MTE is claimed as being necessary for a person or a group (especially the minorities and the marginalised) to be able to achieve their full humanity, in common with others. MTE is also seen as applying to all humanity and it is desired for all people anywhere and everywhere. Further, the human rights discourse in MTE holds the view that MTE is essential for people from the minorities and the marginalised to achieve full human potential. Proponents of the human rights discourse in MTE have been able to mobilise support to the extent that there is substantial universal consensus on the legitimacy of MTE as a human right. They further argue that with proper institutional support, especially from governments, it is possible for MTE as a human right to be realised for all legitimate claimants, especially at the foundational years of education; and that the right to MTE does not contradict other rights. 
Closely related to the human rights discourse in MTE is the social justice discourse. Essentially social justice relates to the principle that every effort should be made to ensure that individuals and groups all enjoy fair access to rewards. It is about creating a more equitable, respectful and just society for everyone. However, social justice is not necessarily about equality. It can be about providing equal opportunities to access an unequal reward structure. In a society committed to the ideals of social justice, it is recognised that fair treatment and equal opportunities for everyone can only be brought about by imposing restrictions on the behaviour of some individuals or groups (Furlong and Cartmel 2009), pp. 3 - 4. From a social justice discourse perspective, MTE is a way of ensuring individuals and groups enjoy fair access to education in a manner that is equitable, respectful and just for everyone.

\section{Development discourse}

Another compelling discourse in MTE is the development discourse, both in its traditional nuance that conceptualised development as 'modernisation' and the contemporary nuance of development as 'human development'. Modernisation posited that all societies' progress in a linear fashion from a traditional state to modernity, with models of development based on historical processes that had taken place in the industrialised world. Historically, modernisation is the process of change towards those types of social, economic and political systems that have developed in Western and North America from the seventeenth century to the nineteenth and have spread to other European countries and in the nineteenth and twentieth centuries to the South American, Asian and African continents. To the newly independent nations of the Third World, it held out the promise of a guided transition to the state of developed industrial society. This perspective embodies a simplistic dichotomy between the traditional and the modern, with modernisation depicted as the process of moving from the former to the latter (Haines 2009). According to UNDP (1999), pp. 15-16:

Human development can simply be seen as a process of enlarging choices. Every day, human beings make a series of choices - some economic, some social, some political, some cultural. If people are the proper focus of development efforts, then these efforts should be geared to enhancing the range of choices in all areas of human endeavour for every human being. Human development is both a process and an outcome. It is concerned with the process through which choices are enlarged, but it also focuses on the outcomes of enhanced choices. Human development thus defined represents a simple notion, but one with far-reaching implications. Development of the people involves building human capacities through the development of human resources. Development for the people implies that the benefits of growth must be translated into the lives of people, and development by the people emphasises that people must be able to participate actively in the processes that shape their lives.

The traditional nuance of development as 'modernisation' explains why in many polities in the developing world MTE is only for the first few years of schooling before transition to education in other languages, usually western languages. Within this framework, MTE is conceptualised as being a simplistic but necessary precursor of education in western languages. This orientation to development which informs many an education system in the developing world accounts for the crises of MTE in 
developing world polities. Human development on its part accounts for the renewed interest in MTE in many polities in the developing world. MTE is conceptualised as an integral part of enlarging people's choices within and outside the education system.

\section{Mother tongue education in Kenya - an overview through time}

All the discourses outlined in the previous section are manifest in MTE literature and research on Kenya. An issue that is also evident in the MTE literature and research on Kenya as Bunyi (2005), p. 131 aptly points out is that:

As in virtually all African countries, the hegemony of the colonial language English in education has remained an enduring legacy of colonialism in Kenya. Current medium-ofinstruction policy in Kenya is that in linguistically homogenous school neighbourhoods, the indigenous language of the area is to be used from standard $1-3$; in linguistically heterogeneous school neighbourhoods, such as is the case in urban areas, the national language Kiswahili or English is to be used. Where indigenous languages or Kiswahili are used as the medium of instruction from standard $1-3$, a switch to English is to be made at the beginning of standard 4 .

The above MTE scenario in Kenya is a result of cumulative policy omissions and commissions through time. Mbaabu (1996) provides a cursory overview of these by documenting that the Phelps Stokes Commission of 1924 recommended the use of only four mother tongues for education in Kenya. These were Kiswahili, Dholuo, Luhyia and Gikuyu. Later on, Nandi was added to cater for all Kalenjin languages. These languages were very few given that the country has approximately forty distinct languages. To cater for the whole country, each of the above mentioned languages had to be used by other related language communities. For example, Kiswahili had to be used in the whole of the Coast Province and Gikuyu had to be used by Kikamba, Kimeru and Kiembu speakers. As the need to use other languages of education dictated, more mother tongues were added to the list. This was the case with the Beecher Report published in 1949. The committee under Archdeacon Beecher had been established to inquire into such issues as the scope, content and methods of African education. The report, which was accepted by the Government in 1950, recommended that textbooks be provided in eight mother tongues (besides Kiswahili). The mother tongues were Kidawida, Kikamba, Gikuyu, Maasai, Kimeru, Nandi (Kalenjin) Oluluyia (Luhyia) and Dholuo. Other languages recognised by the Beecher Report are Giriama, Pokot, Galla, Sagalla, Taveta, Suk, Kisii, Tende, Tesiot, Boran, Turkana, and Somali. For these languages the Beecher Report recommended that textbooks be translated for initial stages only. This tradition of using a few mother tongues and increasing the number as the demand dictates has been followed up to now. The T.K. K (Tujifunze Kusoma Kikwetu - Let us learn our mother tongue) series were introduced in 15 mother tongues in 1968. The fifteen mother tongues are: Tesiot, Dholuo, Ekegusii, Gikuyu, Igikuria, Kalenjin, Kidawida, Kigiryama, Kiswahili, Kikamba, Kimeru, Lulogooli, Lubukusu, Oluluyia and Maasai. The assumption was and still is that the smaller mother tongues would be catered for by larger closely related ones. Currently, a total of twenty-two mother tongues have been identified for use in the education system in Kenya. They include: Tesiot, Dholuo, Ekegusii, Gikuyu, Igikuria, Kalenjin, Kidawida, Kigiryama, Kiswahili, Kikamba, Kimeru, Lulogooli, Lubukusu, Oluluyia, Maasai, Elmaa, Pokot, Sabawoot, Ngaturkana, Somali, Ludirichi, and Kiembu. 


\section{Primary teacher education in Kenya}

Since independence in 1963, the Government of Kenya has committed itself to the provision of adequate, properly trained and motivated primary school teachers. In this respect, the Kenya Education Commission Report of 1964 (commonly known as the Ominde Commission) and subsequent education reports and policy documents have all reiterated the importance of matching teacher supply from various training institutions with the demand in educational institutions. The Sessional Paper No. 6 of 1988 on Education and Manpower Training for the Next Decade and Beyond, in particular, put significant emphasis on quality teacher training. The Sessional Paper No. 1 of 2005 also paid attention to effective teacher development and utilisation (Ministry of Education, Science and Technology - Kenya MOEST 2005). According to the Kenya Education Sector Support Programme (2005 - 2010), there are 21 public primary teachers' training colleges (TTCs) having an enrolment of about 17,000 students and an annual production rate of about 8,500 teachers. This annual output is almost at par with the annual attrition rate which is estimated at 8,000 teachers. The network of TTCs was established by government as part of its commitment to providing qualified, competent and adequate teachers to all primary schools in the country. TTCs are financed primarily through government grants and student subsidies. Some of them also engage in income generating activities. However, for them to operate normally, the government, through the Teachers Service Commission (TSC), meets the tutors' remuneration and provides grants for tuition supplies, teaching practice and salaries for Board of Governors (BOG) employees. The list of TTCs in Kenya is shown in Table 1.

Mbaabu (1996), p. 22 citing Mutua 1987, p.11) documents that "the Kenya primary teacher education curriculum consists of the following 13 subjects: Professional studies; English; Mathematics; Science; Art and Craft; Physical Education; Religious Education (Christian and Islamic); Home Science; Music; Kiswahili; Geography, History and Civics (A combined course); Business Education; and Agriculture". The core courses among these are: Professional studies, English, Kiswahili, Religious Studies, Mathematics, Science and Physical Education. The optional subjects or electives are History, Geography, Agriculture, Home Science, Music, and Arts and Crafts. In addition to the core subjects, each student is expected to take three optional subjects in the second year. This curriculum was first introduced in 1986 and later revised in 1994 and in 2004 after the review of primary school curriculum. "The revised curriculum also addresses emerging issues in

Table 1 Public teacher training colleges (TTCs) in Kenya per province

\begin{tabular}{llll}
\hline Province & Population & No. of TTCs & Names of TTCs \\
\hline Rift Valley & $8,418,100$ & 5 & Narok, Kericho, Mosoriot, Baringo, Tambach \\
Eastern & $5,322,400$ & 5 & Kigari, Meru, Machakos, Kilimambogo, Igoji \\
Nyanza & $4,984,900$ & 3 & Asumbi, Bondo, Migori \\
Western & $4,151,000$ & 2 & Eregi, Kaimosi \\
Central & $3,923,900$ & 3 & Kamwenja, Murang'a, Thogoto \\
Coast & $2,975,400$ & 1 & Shanzu \\
Nairobi & $2,845,400$ & 1 & Highridge \\
North Eastern & $\mathbf{1 , 3 2 6 , 0 0 0}$ & 1 & Garissa \\
Total & $\mathbf{3 3 , 9 4 7 , 1 0 0}$ & $\mathbf{2 1}$ & \\
\hline
\end{tabular}

Source: Central Bureau of Statistics: 2006. 
society such as: HIV and AIDS pandemic; drug and substance abuse; environmental education; human rights including children's rights; gender issues; technology in curriculum delivery; and alternative models of curriculum delivery" (Ministry of Education, Science and Technology - Kenya MOEST 2005), p. 125. Although some scholars contend that there should be an overt reference to pedagogics/didactics of mother tongue in the teacher-training curriculum, these are taught under professional studies in which language teaching (with specific reference to English and Kiswahili language teaching) constitutes a critical part of the curriculum.

\section{The quota system in Kenya's education}

The quota system in Kenya's education has been a target of disparaging critique since it was introduced in the mid 1980s. As Amutabi (2003) documents, the quota system remains one of the most controversial inclusions in Kenya's education system. It was introduced into the country's education system with the selection of students to join Form One, the disbanded Form Five and colleges (diploma and certificate) as from 1985. It was formally endorsed in 1987 . The quota system was precipitated by a number of factors, key amongst them being strategic ethno-political and economic permutations in the period immediately after independence and the post Jomo Kenyatta presidency era. President Jomo Kenyatta, whose ethnic group, the Kikuyu (mainly confined in Central Province), had developed the best schools had just been succeeded by President Moi, whose ethnic group, the Kalenjin (mainly confined in the Rift Valley Province), and others like Western and Coast Provinces has perhaps the worst schools in the whole nation. For instance, during Kenyatta's time in 1977, of the eleven secondary schools that took most students to university, five, namely Kagumo (92), Thika (76), Alliance Boys (72), Alliance Girls (60) and Nyeri (48), were in Central Province. Kagumo with 92 had more qualifiers to university that year than the whole of Western Province schools that had a combined total of 87. After a few years of President Moi's rule, the fortunes of other provinces has changed vis-à-vis Central Province as the President had helped in building the best schools in the country especially among his ethnic group. Kabarak, Sacho, Moi Girls-Eldoret, Kapsabet Boys, Kipsigis Girls, Kabarnet Boys, Kapkenda Girls, were emergent giants and yet the positions in these schools were being shared equitably by students from areas like Central Province that were previously privileged, hence perpetuating the imbalance. This had to stop and the Kikuyu had to be curtailed by confining them to Central Province if the other areas had to catch up.

A 1985 Presidential directive therefore stipulated that each school admits 85\% of its students from the local area. This later on became policy for the Ministry of Education. It was pointed out by the politicians that this new directive would give the local people an opportunity to fully develop the schools in their region, knowing that they would benefit them more than anybody else. But this was a negation of the policy of national integration that was recommended in the Ominde Report of 1964 and to which the education planners had been committed since independence. It had said that local schools were likely to produce strong local and tribal feelings, which are destructive of a sense of nationhood. Amutabi (2003) further documents that the quota system promotes regionalism because it encourages localised approaches to problems and it 
provides the incubation and fertile ground for regional or ethnic nationalism. In an interesting commentary on the impact of the quota system on language-in-education in Kenya, Amutabi (2003), p. 135 submits that "the quota system is blamed for the creeping of vernacular into secondary schools at a very alarming rate. The poor performance in English language exams at the national level can find explanation in this policy".

While acknowledging the import of Amutabi's (2003) analysis, the current discussion does not subscribe to the deductions which can be characterised as simplistic. There are many contingent factors that contribute to the increase in ethnic consciousness and poor performance in foreign languages even in polities that do not have a quota system in place. If anything, contemporary research characterises development trajectories that are overly centralised [the anti-thesis of a quota system] as being responsible for "rootless growth" - which causes people's cultural identity to wither. In some cases minority cultures are being swamped by dominant cultures whose power has been amplified by growth. In other cases governments have deliberately imposed uniformity in the pursuit of nation-building - say, with a national language. This can be dangerous. The violence in the former Soviet Union and in the Balkan states of the former Yugoslavia is a tragic legacy of culturally repressive governance. The nations that have held together best, from Switzerland to Malaysia, are often those that have recognised cultural diversity and decentralised economic and political governance to try and meet the aspirations of all their people (UNDP 1996), p. 4. It is from this perspective of the viability of decentralised/devolved governance structures that the quota system in Kenya's education system is conceptualised as a positive element that can be harnessed for MTE.

\section{Primary teacher education and the quota system in MTE discourses in Kenya}

Two factors contribute to the maintenance of quality in primary teacher training in Kenya. First, curriculum development, monitoring and evaluation are centrally managed by the Kenya Institute of Education (KIE). This ensures a uniform implementation of the curriculum in all the 21 TTCs. Secondly, qualification examinations for all TTCs, which are centrally administered, are the sole preserve of the Kenya National Examinations Council (KNEC). These two factors ensure that, save for individual attributes; a primary school teacher in Kenya is as good as the next one. The implication of these two factors to MTE in Kenya is that all primary school teachers are professionally prepared in a standardised way to actualise MTE.

The quota system can be harnessed in support of MTE in Kenya in two fundamental ways. First, because the quota system is used in the recruitment of teacher trainees it ensures that all Kenya's linguistic communities are represented in the cohort of approximately 8,500 teacher trainees who join and graduate from the 21 TTCs every year. This translates to having all the mother tongues spoken in Kenya represented in the primary teacher training system. In effect, every linguistic community in Kenya has a pool of qualified primary school teachers who can effectively teach mother tongue and teach in mother tongue. The net result of this dynamic is that teachers from Kenyan TTCs can teach effectively in their own mother tongues. Secondly, with the quota system being in place in the recruitment of teachers where the responsibility of teacher recruitment is delegated to school committees of primary schools, the tendency of school 
committees is to recruit teachers who hail from the catchment area of the school. The probability of such teachers being conversant with the language of the catchment area (effectively the designated mother tongue of the school) is very high.

\section{Conclusions (policy and pragmatic lessons)}

In the introduction it was observed that in line with the core preoccupation of language management of seeking to formulate approaches and/or frameworks that can be deployed to harness language resources in society, quality primary teacher education and the quota system can be harnessed to address the MTE quandary in Kenya, and possibly elsewhere. The preceding discussion illustrates this observation. The discussion also brings to the fore the following:

i. Language management provides a versatile framework of interrogating the dynamics attendant to language in society in general and language-in-education specifically.

ii. Discourse is an important construction in interrogating phenomena. It is critical in seeking to understand and analyse language-in-education dynamics in general and MTE in particular.

iii. Quality primary teacher education is a basic requirement in actualising MTE in any polity.

iv. The notion of quotas, controversial as it may be, can be harnessed to positively advance MTE agenda.

v. There is need for ethnographic and phenomenological research to investigate and document what works and what does not work for MTE in different polities.

MTE discourse is critical and is bound to remain so for a long time especially in the developing world. That this is the case is hardly surprising for as Mwaniki (2010) pointedly submits, more than a century after the onset of the colonial project in much of the developing world that has unequivocally sought to replicate the ethnolinguistic homogenisation project of Western and Central Europe, it can safely be submitted that this project has failed to produce the 'desired' results of ethnolinguistic homogenisation. Despite polities in the developing world pursuing unilingual and/or bilingual policies which are largely inimical to MTE, multilingualism has not vanished in this part of the world. It may just be time to acknowledge failure of the ethnolinguistic homogenisation project of the last 100 years; and the viability and resilience of multilingualism the developing world. Such an acknowledgement will signal a new dawn for MTE in the developing world. A resurgent MTE discourse will greatly benefit from language management. 


\section{References}

Amutabi, MN. 2003. Political interference in the running of education in post-independence Kenya: a critical retrospection. International Journal of Educational Development 23:127-144.

Bamgbose, A. 2009. Foreword. In Languages and education in Africa: a comparative and transdisciplinary analysis, ed. B Brock-Utne and I Skattum, 13-14. Oxford: Symposium Books.

Blaug, M. 1979. Economics of education in developing countries: current trends and new priorities. Third World Quarterly 1(1):73-83.

Bunyi, GW. 2005. Language classroom practices in Kenya. In Decolonisation, globalisation: language-in-education policy and practice, ed. AMY Lin and PW Martin, 131-152. Clevedon: Multilingual Matters Ltd.

Central Bureau of Statistics. 2006. Kenya: Facts and figures. Nairobi: Central Bureau of Statistics.

Clignet, R. 1970. Inadequacies of the notion of assimilation in African education. The Journal of Modern African Studies 8(3):425-444.

Dovlo, D. 2004. The brain drain in Africa: an emerging challenge to health professionals' education. JHEA/RESA 2(3):1-18.

Duminy, PA, and WF Sohnge. 1982. Didactics: Theory and practice. Longman Penguin Southern Africa (Pty) Ltd: Cape Town.

Dunn, WN. 1981. Public policy analysis: An introduction. Englewood Cliffs, N. J. Prentice-Hall.

Foster, P. 1980. Education and social inequality in Sub-Saharan Africa. The Journal of Modern African Studies 18(2):201-236.

Furlong, A, and F Cartmel. 2009. Higher education and social justice. Maidenhead, Berkshire: Open University Press McGraw-Hill Education.

Gould, WTS. 1974. Secondary school admissions policies in Eastern Africa: some regional issues. Comparative Education Review 18(3):374-387.

Haines, R. 2009. Development theory. In F. D. Beer \& H. Swanepoel (Eds.), Introduction to development studies, (2nd ed.), Eleventh Impression (pp. 31-60). Cape Town: Oxford University Press.

Harmse, HJ. 1982. Pedagogics (Part 1). Durban: Butterworths.

Ife, J. 2001. Human rights and social work: Towards rights-based practice. Cambridge: Cambridge University Press. Kymlycka, JD. 1995. Multiculturalism: The issues and the basics. St. Paul, MN: Eagan Press.

Martin-Jones, M, and AM De Mejia. 2008. Introduction to volume 3: Discourse and education. In Encyclopedia of Language and Education, vol. 3, 2nd ed, ed. M Martin-Jones, AM De Mejia, and NH Hornberger. New York: Springer Science+Business Media, LLC. Discourse and Education (pp. xiii - xxxii).

Mbaabu, I. 1996. Mother-tongue in education. Nairobi: Lectern Publications Ltd.

Ministry of Education, Science and Technology - Kenya (MOEST). 2005. Kenya education sector support programme: Delivering quality education and training to all Kenyans. Nairobi: MOEST.

Morley, L, F Leach, and R Lugg. 2009. Democratising higher education in Ghana and Tanzania: opportunity structures and social inequalities. International Journal of Educational Development 29: 56-64.

Mutua, R. 1987. Information on primary teacher training colleges project. Workshop on the training of trainers in educational planning for English speaking countries of eastern and southern Africa. Nairobi: 22 June - 10 July 1987.

Mwaniki, M. 2004. Language planning in South Africa: towards a language management approach (unpublished Ph.D. Thesis). Bloemfontein: University of the Free State.

Mwaniki, M. 2010. MIDP IV: An adventure in language management. In MIDP IV: Report on activities in the Xhariep (2008-2010), ed. S Lombaard, 57-69. Bloemfontein: Sun Media.

Neustupny, JV. 1968. Some general aspects of 'language' problems and 'language' policy in developing societies. In Language problems of developing nations, ed. JA Fishman, CA Fergusson, and J Das Gupta, 285-294. New York: Wiley.

Neustupny, JV. 1978. Post-structural approaches to language. Tokyo: University of Tokyo Press.

Neustupny, JV. 1983. Towards a paradigm for language planning. Language Planning Newsletter 9(4):1-4.

Neustupny, JV. 1984. Literacy and minorities: Divergent perceptions. In Linguistic Minorities and Literacy, ed. F Coulmas, 115-128. Berlin: Mouton

Neustupny, JV. 1985. Problems in Australian-Japanese contact situations. In Cross-cultural encounters: Communication and mis-communication, ed. JB Pride, 44-64. Melbourne: River-Seine.

Neustupny, JV. 1989a. Language purism as a type of language correction. In The politics of language purism, ed. BH Jernudd and MJ Shapiro, 211-223. Berlin: Mouton de Gruyter.

Neustupny, JV. 1989b. Czech diglossia and language management. New Language Planning Newsletter 3(4):1-2.

Neustupny, JV. 1993. Language management for Romani in Central and Eastern Europe. New Language Planning Newsletter 3(4):1-2

Neustupny, JV. 1995. Some issues of ordering in interactive competence. In Proceedings of LP'94: Item order in natural languages, ed. B Palek, 10-26. Prague: Charles University.

Neustupny, JV. 1999. Sociolinguistics and the Prague School. In Prague Linguistic Circle Papers 3, 275-286. Amsterdam/ Philadelphia: John Benjamins.

Neustupny, JV, and J Nekvapil. 2003. Language management in the Czech Republic. Current Issues in Language Planning 4(3):181-366.

Opiyo, D. 2010. Raila wants quota system abolished. Daily nation. Accessed 18 September 2011. http://archives. in2eastafrica.net/raila-wants-quota-system-abolished/.

Siringi, S. 2011. Pupils exodus feared from private to public schools. Daily Nation. Accessed 18 September 2011. http://allafrica.com/stories/201101170142.html.

Spolsky, B. 2009. Language management. Cambridge: Cambridge University Press.

Tanye, M. 2008. Access and barriers to education for Ghanaian women and girls. Interchange 39(2):167-184.

Ukiwo, U. 2007. Education, horizontal inequalities and ethnic relations in Nigeria. International Journal of Educational Development 27:266-281

UNDP. 1996. Human development report 1996. New York: Oxford University Press.

UNDP. 1999. Human development report 1999. New York: Oxford University Press. 
UNESCO. 1951. Report of the UNESCO meeting of specialists, 1951: The use of vernacular languages in education. In J. A. Fishman (Ed.), 1972. Readings in the sociology of language (pp. 688-716). The Hague: Mouton. Van Der Waldt, G. 2002. Public policy and policy analysis. In Governance, politics, and policy in South Africa, ed. D van Niekerk, G van Der Waldt, and A Jonke, 86-114. Cape Town: Oxford University Press.

Yakaboski, T, and K Nolan. 2011. The Kenyan school systems' impact on public higher education access: Examination of growth, access, and challenges. Journal of International Education and Leadership 1(1):1-13.

doi:10.1186/s13616-014-0011-4

Cite this article as: Mwaniki: Mother tongue education in primary teacher education in Kenya: a language management critique of the quota system. Multilingual Education 2014 4:11.

Submit your manuscript to a SpringerOpen ${ }^{\odot}$ journal and benefit from:

- Convenient online submission

- Rigorous peer review

- Immediate publication on acceptance

- Open access: articles freely available online

- High visibility within the field

- Retaining the copyright to your article 